\title{
Innovation-based Reform for Teaching Model of Chemical Engineering Major in Secondary Vocational Schools
}

\author{
Xueping Zhou \\ Jiangde Industrial Technology School, Hangzhou, Zhejiang, 311612
}

Keywords: Chemical engineering teaching, Vocational educationl innovation and reform.

\begin{abstract}
The secondary vocational education aims to cultivate talents meeting demands of socialist modernization, while with instant development of market economy presently, the social demands for secondary vocational talents increasingly tend towards inter-disciplinary talents and applied talents. The traditional pattern of secondary vocational education is dominated by cultivating of students' theoretical knowledge, which does not tally with social demands. The secondary vocational education should conform to the times by innovating the educational pattern to cultivate modernized talents with high quality and skills. Thus, the author explores innovation and reform of chemical engineering teaching models in secondary vocational education, in the hope of contributing to reform of higher vocational education in future.
\end{abstract}

\section{Introduction}

The major of chemical engineering in secondary vocational schools mainly cultivates high-quality talents fit for the industry of chemical engineering. The students will learn related courses to master the theoretical knowledge of this major and basic practical ability. Nevertheless, the teaching actuality of chemical engineering in many secondary vocational schools shows a lot of drawbacks and cannot meet the social demands for talents any more with contradiction existing between the cultivated talents and the demands of HR market. To cope, the teachers of chemical engineering in the secondary vocational schools should seek for a policy of innovation and reform conforming to actuality of the secondary vocational schools, improve teaching quality, so as to cultivate modern talents of chemical engineering conforming to current social wants in a real sense.

\section{Analysis on status quo of chemical engineering teaching in secondary vocational schools}

The chemical engineering courses in secondary vocational schools mainly help students to master basic chemical principles, fully understand production flow of chemical products, and improve students' manual ability for manufacturing machine in this industry. Yet due to certain limitation of teaching models and too vapid and dull teaching ways, the students' learning enthusiasm cannot be fully aroused, let alone effective improvement on students' major level. Thus the cultivated talents are limited to application of theoretical knowledge and have poor practical ability, even some students' mastering of basic theoretical knowledge is very unsatisfactory.

The enterprises require increasingly high on talents with progressive development of socioeconomy. However, a great many teachers just adopt simple teaching media and single mode, "repeat what the book says" and only value imparting of theoretical knowledge to students without teaching media integrating theory and practice, leading to the cultivated students to be incompetent for the current chemical engineering market which requires high on professionalism The reason to explain this is that the major of chemical engineering itself requires high on the students' actual operation capacity and professional ability, while solely imparting of theoretical knowledge is impossible to rapidly cultivate students who are competent for actual operation in future work. Besides, this will waste a lot of time as the students have to learn the operation skills on post, which 
should have been done at school.

Teachers serve as the major participators of chemical engineering teaching in secondary vacational education, so their teaching level and awareness of innovation and reform largely determine the direction and progress of education reform. But currently many teachers in the secondary vocational schools stick to stereotype by continuing to use the old teaching models, and learn from other excellent teaching models, which, however, is just copying rigidly, and there is devoid of practice in own students. This scene is prevalent in old teachers, while the young ones lack experience with students, let alone innovation and reform of teaching.

\section{Clue of innovating and reforming the teaching models of secondary vocational education}

Firstly, to carry out educational reform, the schools must be cognizant of the drawbacks in current teaching and establish a complete mechanism for innovation and reform of teaching to guarantee the measures of innovation and reform are implemented. Thus, the secondary vocational schools should set a work team of teaching innovation and reform covering vice-president of teaching-teaching administration-innovation teaching department-teachers. and establish dedicated office of teaching innovation and reform to guarante smooth implementation of innovation and reform planning grade by grade from school, grade to class. Secondly, the schools should examine each link of teaching innovation and reform and encourage the teachers to innovate and reform. The teachers making significant contribution to teaching innovation and reform should be awarded some material and spiritual reward to enhance their enthusiasm in this drive.

Teachers serve as the major participators of teaching innovation and reform, so their teaching level and innovation ability largely determine the success of teaching innovation and reform. However, currently the teachers' teaching level and innovation ability want improvement due to lack of teachers in the secondary vocational schools, weak innovation awareness of old teachers and lack of teaching experience in young teachers. Thus, the schools should formualte training plan of teachers based on innovation and reform of teaching, actively dispatch teachers to go out for learning and training, invite some veteran experts in innovation and reform of teaching to give lecture, expand recruitment avenues of young teachers, and attract young teachers with expertise and proficient skills by dint of better development opportunities and treatment.

The innovation and reform of teaching models should not be limited to teaching forms and methods, but should extend to courses system and instructional resources, to reform past courses system and instructional resources not conforming to students' practical situation. Besides, the experience in innovation and reform of teaching should be relentlessly summarized to structure courses system in line with the actual situation of current secondary vocational schools and the students. And we should adopt teaching content and teaching method in which the students are interested in to fully arouse their learning enthusiasm, in an effort to improve students' learning efficiency via a comprehensive and perfect courses system and rich instructional resources.

Firstly, we should arouse students' interest with "activity method of teaching". As the students of secondary vocational schools prevalently have poor cultural base and strong learning-weariness, the schools should innovate teaching and put many efforts in constructing "activity curriculum", stress "education is just life" and "school is just society", and we should combine the discipline characteristics of innovation education to arouse students' learning initiative and encourage them to aggressively explore, then they can "learn by doing and do by learning" to learn the required knowledge and skills well. Secondly, the "case teaching" should be adopted to inspire the students' innovation idea. As the technology invention is innovation-based, we should graft the "case teaching" widely applied to management science and law science to innovation education and apply it innovatively. The teachers should analyze, compare and research the experience of success and failure of various innovations and inventions to abstract and induce general methods and principles for innovation and inventions, encourage students to widen own view via own or others' thinking, inspire innovation idea, thereby improving own innovation ability. Lastly, the school should introduce "project teaching" to improve students' practical ability. After all, the cultivation of innovation ability must be embodied in innovation practice. The innovative teaching should 
introduce "project teaching method" and then make students digest, absorb and use the knowledge. In the teaching practice, the process from "excogitating a project", "conceiving and designing" to "writing down (scheme)" and drawing up (flow) and finally to fabricating the "real sample" just fully embodies the requirements of innovation quality and innovation ability and can effectively improve students' innovation and practical ability, also can spark their passion for actively participating in exploration and cultivate their spirit of independent cooperation and innovation as well as exploration.

Holding various activities, which are among important bearers of teaching, is an all-important form for teaching to make students participate in experience activities. Thus, we can embed the innovation teaching in various intracurricular and extracurricular activities, such as festival of science and technology culture, public day of innovative education, exhibition of excellent harvest, visit to enterprises and science and technology exhibitions, series thematic activities of scientific research, team exchange, scientific-technical service for communities, etc., through which to actively cultivate students' innovation awareness and ability. Besides, the school should place a high premium on holding varioius contests and award those delivering good results some incentives, to set innovation model, thereby generating innovation heat and forming a good atmosphere of every body participating in and talking about innovation.

\section{Concrete suggestions for innovation and reform of chemical engineering teaching in secondary vocational education}

One important move to reform the curriculum model of chemical engineering teaching in secondary vocational education is intensifying laboratory courses. The practice of rationale of chemical engineering is the marrow in the whole system of chemical engineering teaching, so the teachers should aggressively and reasonably arrange for students to receive training in experimental skills and give them opportunities of operating personnally in class. The teachers should seek to enhance students' innovation ability, comprehensive practical ability and manual operation capacity via standard demonstration. The schools should actively contact the chemical engineering enterprises to enhance cooperation and timely know the ultramodern ideas of the major, new chemical instruments and chemical engineering flow, to combine the chemical practice in the society with theoretical knowledge, thereby significantly enhancing the practicability and applicability of chemical engineering courses, steadily improving students' comprehensive quality and employment capacity by teaching them to apply the theoretical knowledge to practice.

As an importent element in teaching activity, the teachers of chemical engineering combines knowledge and own practice of chemical engineering based on own quality and level, then impart the $\mathrm{ABC}$ of chemical engineering to students, which process forms high requirements on the chemical engineering teachers in secondary vocational schools and drives them to relentlessly improve own cultural quality, expand own knowledge base, learn more and absorb fresh elements. The teachers need to accumulate substantive practice experience in chemical engineering, production experience and knowledge of chemical engineering, professional expertise, know the market demand for this major, then set major courses system suitable for students according to various demands in the domain together with the professionals.

The secondary vacational schools should cultivate professional talents of chemical engineering and lay stress on utility-type talents of this major. The schools should be centered on students to overbearingly improve their professional capacity. In teaching practice, the teachers can adopt teaching method of cooperation and discussion to make students exchange learning perception, get deeper impression and understanding about the major. The students can be actively fused into class, thereby transforming the pattern of passive listening to active participation. This reversal of learning pattern can help to accomplish teaching mission and improve learning quality in the class, enhance exchange among studets and raise problem-solving ability, thus this plays a decisive role in cultivating students' professional capacity of chemical engineering.

Firstly, to cope with the prevalent problems of poor learning base and strong learning-weariness among the students in secondary vocational schools, the "activity method of teaching" should be 
adopted to spark their interest, such as organizing contests in teaching to make students participate in practice teaching of chemical engineering by dint of group contests, etc. to improve their practical ability. Secondly, the "case teaching" method should be employed to inspire their innovation thinking, with practical cases fused into chemical engineering teaching, to improve students' comprehension and analysis capability for practical problems. Of course, the "project teaching" can also be introduced to improve students' practical ability, i.e. the teacher assigns an independent chemical engineering mission to students, and helps the students to master the concrete operations flow of mission and corresponding practical ability via data collection, design of project plan, implementation of project skills and project evaluation, etc.

Development and organization of experience activities of chemical engineering teaching help students to acquire a deeper understanding about this major, such as festival of science and technology culture related to chemical engineering, exhibition of excellent chemical engineering works, visit to chemical engineering enterprises, series thematic activities of chemical engineering research, team exchange, to cultivate students' strong innovation awareness and ability. The teachers and students doing good job should be awarded some material and spiritual incentives to encourage more teachers and students to participate in these activities.

\section{Conclusion}

As society increasingly requires high on talents, the secondary vocational schools must reform past backward teaching models, make innovation and reform, with courses system, instructional resources, teaching mechanism, teaching method, teachers resources, etc. as breakthrough, to cultivate modernized talents with high quality and skills.

\section{References}

[1] Liu Xiaorong. Reform of Teaching Model for the Courses of Chemical Engineering in Secondary Vocational Schools [J] New Course. 2 ,2016(07):153-153.

[2] Lin Jieyu. A Brief Analysis on Several Transformations in Reform and Innovation of Secondary Vocational Teaching [J] Guangxi Vocational and Technical Education and Research. 2010(04):7-8.

[3] Peng Zhibin, Wang Zhicun, Yuan Jiyu, Chen Dong, Yuan Changhong, et al., Innovational Educational Reform and Practice for Secondary Vocational Schools [J]. China Vocational and Technical Education. 2015(07):63-66.

[4] Ji Honglou, Implementation of Teaching Model Reform for the Courses of Chemical Engineering in Secondary Vocational Schools [J]. Modern Vocational Education. 2015(15):41-41. 